\title{
Aspectos Quantitativos da Deposição de Gotas de Pulverização em Plantas de Amendoim e Brachiaria plantaginea ${ }^{1}$
}

\author{
Quantitative Aspects of Spray Droplet Deposition on Peanut Plants and Brachiaria plantaginea
}

\author{
RODRIGUES-COSTA, A.C.P. ${ }^{2}$, MARTINS, D. ${ }^{3}$, COSTA, N.V. ${ }^{4}$ e PEREIRA, M.R.R. ${ }^{5}$
}

\begin{abstract}
RESUMO - Objetivou-se avaliar a deposição de gotas de pulverização em plantas de amendoim (Aracahis hypogaea) e Brachiaria plantaginea, presentes na linha e entrelinhas de semeadura da cultura, além da deposição no solo. O estudo foi realizado em campo no cultivar de amendoim IAC Tatu-ST, sendo as aplicações dos tratamentos realizadas nos estádios vegetativo (V1) e reprodutivo (R2). Foi utilizado como marcador o corante Azul Brilhante (FD\&C-1), na concentração de $500 \mathrm{ppm}$. Os tratamentos foram constituídos por sete pontas de pulverização: XR 110015 VS (150 L ha $\left.{ }^{-1}\right)$, XR 11002 VS (200 L ha-1), TX-VK 6 (150 L ha-1), TX-VK 8 (200 L ha-1), AI 110015 VS (150 L ha-1), AI11002 VS (200 L ha-1) e TJ60 11002 VS (150 e $200 \mathrm{~L} \mathrm{ha}^{-1}$ ). Utilizou-se o delineamento em blocos ao acaso, com quatro repetições. Os resultados evidenciaram que: a pulverização de maiores volumes de calda proporcionou incrementos nos depósitos sobre plantas do cultivar IAC Tatu ST em ambos os estádios de desenvolvimento da cultura, com exceção das pontas XR 110015 VS e AI11002 VS nos estádios vegetativo (V1) e reprodutivo (R2) da cultura, respectivamente; as maiores perdas de gotas para o solo nas aplicações no estádio vegetativo (V1) foram proporcionadas pelas pontas AI 110015 VS e AI 11002 VS, e no estádio reprodutivo (R2) a ponta XR 11002 VS foi a que promoveu maior perda; e as pontas XR 11002 VS, AI 110015 VS e TJ60 11002 VS (150 L ha-1) proporcionaram os maiores depósitos nas plantas de B. plantaginea na linha em relação às da entrelinha da cultura nas aplicações no estádio vegetativo (V1), enquanto no estádio reprodutivo (R2) as pontas apresentaram comportamento semelhante entre si na deposição de gotas sobre a planta daninha.
\end{abstract}

Palavras-chave: ponta de pulverização, tecnologia de aplicação, planta daninha, uniformidade de deposição.

ABSTRACT - The objective of this study was to evaluate the amount of spray deposition on peanut plants (Aracahis hypogaea) and on the weed Brachiaria plantaginea, in the rows and inter rows of the culture, as well as the amount of deposition on the soil. The study was conducted in the field using the peanut cultivar IAC Tatu-ST and the treatment applications were performed at the vegetative (V1) and reproductive (R2) stages. Brilliant Blue (FD\&C-1) was used as tracer in water solution, at $500 \mathrm{ppm}$. The treatments were constituted of seven spray nozzles: XR $110015 \mathrm{VS}$ (150 L ha-1), XR 11002 VS (200 L ha-1), TX-VK 6 (150 L ha-1), TX-VK 8 (200 L ha-1), AI 110015 VS (150 L ha-1), AI1 $1002 \mathrm{VS}\left(200 \mathrm{~L} \mathrm{ha}^{-1}\right)$ and TJ60 $\left.11002 \mathrm{VS} \mathrm{(150} \mathrm{and} 200 \mathrm{~L} \mathrm{ha}^{-1}\right)$. A randomized block design was used, with four replications. The results showed that the application of a larger spray volume increased the amount of depositions on the plants IAC Tatu ST at both stages of crop development, with the exception of spray nozzles XR 110015 VS and AI1 1002 VS, at the vegetative (V1) and reproductive (R2) stages of the culture, respectively; the greatest loss of drops in applications on the soil at the vegetative stage (V1) was provided by the spray nozzles AI 110015 VS and AI $11002 \mathrm{VS}$; however, at the reproductive stage (R2), the spray nozzle XR 11002 VS caused the greatest loss; The spray nozzles XR 11002 VS, AI 110015 VS, and TJ60 11002 VS (150 L ha-1) provided higher depositions on the leaves of $\boldsymbol{B}$. plantaginea planted in the row than between the rows in the applications at the vegetative stage (V1), while at the reproductive stage (R2), the spray nozzles showed similar results for the deposition of droplets on the weed.

Keywords: spray nozzle, application technology, weed, deposition uniformity.

1 Recebido para publicação em 15.1.2011 e aprovado em 13.8.2011.

2 Bolsista Pós-Doutorado, UNIOESTE/CCA, Caixa Postal 91, 85960-000 Marechal Cândido Rondon-PR, <andreiacpr@hotmail.com>; ${ }^{3}$ Professor Adjunto, Dep. de Produção Vegetal, Faculdade de Ciências Agronômicas - FCA/UNESP, Fazenda Lageado, Caixa Postal 237, 18603-970 Botucatu-SP; ${ }^{4}$ Professor Adjunto, UNIOESTE/CCA, Marechal Cândido Rondon-PR; ${ }^{5}$ Bolsista Pós-Doutorado, FCA/UNESP, Botucatu-SP.

Planta Daninha, Viçosa-MG, v. 30, n. 1, p. 201-209, 2012 


\section{INTRODUÇÃO}

A cultura do amendoim (Aracahis hypogaea) é cultivada em todo o território brasileiro, geralmente em áreas de renovação de canaviais e de pastagens. Nas regiões Centro-Oeste, Sul e Sudeste podem-se obter duas safras por ano (águas e seca). De acordo com estimativas do IBGE (2010), a produção brasileira de amendoim no ano agrícola 2009/ 10 foi de $266,8 \mathrm{mil}$ toneladas, cultivados em 108,2 mil hectares; destaca-se o Estado de São Paulo, que contribui com $81,6 \%$ da produção nacional e tem rendimento médio de $2.691 \mathrm{~kg} \mathrm{ha}^{-1}$.

Além de possuir elevado valor nutricional, os grãos do amendoim podem conter entre 40 e $50 \%$ de teor de óleo, ressaltando sua importância como fonte alimentar e/ou como matéria-prima para produção de biocombustiveis. Contudo, a produtividade média em várias regiões do País é considerada baixa, em razão de fatores edafoclimáticos, fitotécnicos, incidência de pragas e doenças, bem como devido à interferência de plantas daninhas.

A interferência de plantas daninhas na cultura do amendoim pode reduzir de 10,5 a $92 \%$ a produtividade de grãos (Kasai et al., 1997; Agostinho et al., 2006; Dias et al., 2009). Dessa maneira, a utilização de herbicidas para controle das plantas daninhas destacase como alternativa eficiente, considerando principalmente extensas áreas de cultivo; todavia, ainda há pouca informação na literatura sobre técnicas adequadas de aplicação na cultura do amendoim.

Estudos sobre a eficiência das pulverizações demonstraram que pode haver perdas por deriva entre 49 e $88 \%$ do total do produto aplicado (Pergher \& Gubiani, 1995; Pergher et al., 1997; Chaim et al., 2000; Souza et al., 2007; Farinha et al., 2009; Rodrigues et al., 2010). Dessa forma, considerando o manejo de plantas daninhas, a ocorrência de perdas de produto durante as operações de pulverização pode resultar em falhas de controle, seleção de biótipos resistentes a herbicidas, além de contaminações ambientais diretas e indiretas.

De acordo com Souza et al. (2007), a presença de plantas daninhas próximas à linha da cultura pode promover irregularidades nos depósitos das gotas pulverizadas, exigindo aumentos na dose de herbicidas para que niveis de controle satisfatórios sejam alcançados em campo.

Independentemente da finalidade das operações de pulverização, controle de agentes patogênicos, insetos ou de plantas daninhas, a maior deposição no alvo depende de fatores como volume de aplicação, tipo de ponta de pulverização, abertura da ponta, além de características inerentes ao tipo de alvo, como: estruturas morfoanatômicas foliares, arquitetura do dossel da planta, estádios fenológicos suscetiveis e local preferencial de incidência da doença ou do inseto na planta (Holloway, 1970; Taylor \& Shaw, 1993; Berni et al., 1999; Villalba et al., 2009).

Entretanto, a eficiência do tratamento fitossanitário com a utilização de produtos de ação sistêmica ou de contato não depende somente da quantidade de produto ativo depositado sobre o alvo, mas também da uniformidade de distribuição, sendo a atribuição do processo de aplicação distribuir homogeneamente o produto no alvo. Assim, o presente trabalho teve por objetivo avaliar a deposição de gotas pulverizadas sobre plantas de amendoim e Brachiaria plantaginea, presentes na linha e nas entrelinhas de semeadura da cultura, além da perda de gotas para o solo.

\section{MATERIAL E MÉTODOS}

O presente estudo foi instalado e conduzido em campo, na Fazenda Experimental Lageado, em área denominada "Didática", da Faculdade de Ciências Agronômicas - FCA/UNESP, campus de Botucatu-SP, no ano de 2006. As coordenadas geográficas da área são: latitude de 2207'56" S e longitude de 7466'84" WGr., com altitude média de $762 \mathrm{~m}$, precipitação média anual de $1.517 \mathrm{~mm}$ e temperatura média anual de $20,6^{\circ} \mathrm{C}$.

O experimento foi realizado em área de solo argiloso, classificado como Nitossolo Vermelho Estruturado, de acordo com o Sistema Brasileiro de Classificação de Solos (Embrapa, 1999), com as seguintes características: $\mathrm{pH}$ $\left(\mathrm{CaCl}_{2}\right)=5,7$; matéria orgânica $\left(\mathrm{g} \mathrm{dm}^{-3}\right)=18,2$; $\mathrm{P}\left(\mathrm{MG} \mathrm{dm}^{-3}\right)=38,5 ; \mathrm{H}+\mathrm{Al}, \mathrm{K}, \mathrm{Ca}, \mathrm{Mg}, \mathrm{SB}$ e CTC $\left(\mathrm{mmol}_{\mathrm{c}} \mathrm{dm}^{-3}\right)=28,5 ; 3,9 ; 25,0 ; 11,0 ; 39,9$ e 68,4, respectivamente; e $\mathrm{V} \%=58,0$. 
Utilizou-se como cultura comercial o amendoim, cultivar IAC Tatu-ST, pertencente ao tipo Valência, que possui hábito de crescimento ereto e ciclo vegetativo curto, entre 90 e 110 dias. Antes da instalação do experimento, foi realizada uma aração e uma gradagem com grade pesada, além de duas operações com grade niveladora. Para a adubação, foram aplicados $160 \mathrm{~kg} \mathrm{ha}^{-1}$ de fertilizante, fórmula 04-14-08. Por um período de 14 dias após a semeadura (DAS) foi utilizada irrigação por aspersão com turno de rega em regime de dias alternados, para aplicação de lâmina d'água de $15 \mathrm{~mm}$.

O cultivar de amendoim IAC Tatu ST foi semeado em 18/1/2006, no espaçamento de $0,5 \mathrm{~m}$ entre linhas e 21 sementes por metro, para se obter a densidade de 14 a 15 plantas por metro. Antes da semeadura foi realizado o tratamento de sementes, com thiran (40 g i.a. $100 \mathrm{~kg}^{-1}$ de semente).

As plantas espontâneas de $B$. plantaginea permaneceram em convivência com a cultura durante todo o período experimental; semanalmente, foram retiradas manualmente outras espécies que se encontravam na área de cada parcela, para evitar interferência nos resultados.

Para avaliação da deposição de gotas, a pulverização foi realizada aos 16 DAS da cultura do amendoim, correspondendo à primeira época, e aos 31 DAS, correspondendo à segunda época. Na ocasião das pulverizações, na primeira e segunda épocas, as plantas de amendoim encontravam-se nos estádios vegetativo (V1) e reprodutivo (R2), respectivamente, conforme descrição de Boote (1982). Já a planta daninha $B$. plantaginea apresentava de $1-2$ e 3-4 perfilhos e densidade média da população de 16 e 12 plantas $\mathrm{m}^{-2}$, respectivamente para cada época de aplicação. Na Tabela 1 estão descritos os tratamentos utilizados no experimento, em cada época de aplicação.

Os tratamentos foram aplicados com o auxílio de um pulverizador costal, pressurizado a $\mathrm{CO}_{2}$, equipado com uma barra com quatro bicos, espaçados de 0,5 m. Durante as pulverizações, as parcelas foram protegidas com auxílio de painéis formados com lona plástica $(1,5 \times 2,5 \mathrm{~m})$, a fim de evitar possivel deriva para as parcelas vizinhas.

Nas avaliações dos depósitos nas plantas foi utilizado o corante Azul Brilhante (FD\&C 1). A preparação da calda foi realizada a partir da diluição em água destilada do corante Azul Brilhante, na proporção de $500 \mathrm{mg} \mathrm{L}{ }^{-1}$.

As condições meteorológicas durante as aplicações variaram entre 28,9 e $33,9{ }^{\circ} \mathrm{C}$ de temperatura e de 33 a $65 \%$ de umidade relativa do ar, e a velocidade média do vento foi de $2,5 \mathrm{~km} \mathrm{~h}^{-1}$.

Caixas plásticas tipo gerbox, com dimensões de $11,5 \times 11,5 \times 3,0 \mathrm{~cm}$, foram utilizadas como alvo não biológico e colocadas em cada parcela experimental, com o objetivo de avaliar a quantidade de calda depositada no solo. As caixas foram distribuídas antes das aplicações dos tratamentos nas quatro linhas

Tabela 1 - Descrição dos tratamentos utilizados no experimento, em cada época de aplicação. Botucatu-SP, 2006

\begin{tabular}{|l|l|c|c|c|c|}
\hline \multirow{2}{*}{ Ponta* } & \multirow{2}{*}{ Descrição } & $\begin{array}{c}\text { Volume de } \\
\text { aplicação }\end{array}$ & Vazão da ponta & Pressão & Velocidade \\
\cline { 2 - 5 } & & $\left(\mathrm{L} \mathrm{ha}^{-1}\right)$ & $\left(\mathrm{L} \mathrm{min}^{-1}\right)$ & $(\mathrm{KPa})$ & $\left(\mathrm{km} \mathrm{h}^{-1}\right)$ \\
\hline XR Teejet & XR 110015VS & 150 & 0,45 & 175 & 3,6 \\
\hline XR Teejet & XR 11002VS & 200 & 0,60 & 175 & 3,6 \\
\hline Conejet & TX-VK6 & 150 & 0,50 & 500 & 4,0 \\
\hline Conejet & TX-VK8 & 200 & 0,67 & 500 & 4,0 \\
\hline AI Teejet & AI 110015VS & 150 & 0,45 & 200 & 3,6 \\
\hline AI Teejet & AI 11002VS & 200 & 0,60 & 200 & 3,6 \\
\hline Twinjet & TJ60 11002VS & 150 & 0,60 & 175 & 4,8 \\
\hline Twinjet & TJ60 11002VS & 200 & 0,60 & 175 & 3,6 \\
\hline
\end{tabular}

* Spraying Systems Co. (2003). 
centrais da parcela, sendo colocados quatro gerbox nas linhas e quatro nas entrelinhas da cultura.

Imediatamente após a pulverização, foram coletadas ao acaso, em cada parcela, 25 plantas de amendoim, além de 25 plantas de $B$. plantaginea presentes na linha e 25 plantas nas entrelinhas da cultura. As plantas foram coletadas individualmente rentes ao solo, com o auxílio de pinças e tesouras, sendo posteriormente acondicionadas em sacos plásticos devidamente etiquetados e, em seguida, levadas ao laboratório para serem lavadas com água destilada, para quantificação do traçador. As caixas gerbox provenientes de cada parcela experimental receberam o mesmo procedimento.

No laboratório, frascos plásticos de cor âmbar com capacidade para $250 \mathrm{~mL}$ continham 100 e $150 \mathrm{~mL}$ de água destilada para lavagem das plantas, nos estádios de desenvolvimento vegetativo (V1) e reprodutivo (R2), respectivamente. A água foi colocada no saco plástico contendo a planta; em seguida, este foi agitado durante 25 segundos, devolvendose em seguida a solução para os frascos. Para determinação da massa seca, as plantas foram colocadas em sacos de papel e levadas a uma estufa de ventilação forçada para secagem por um período de 72 horas, em temperatura de $65 \pm 2{ }^{\circ} \mathrm{C}$.

Os frascos plásticos com as amostras do traçador extraído das plantas coletadas foram devidamente armazenados em uma sala escura. Posteriormente, procedeu-se a leituras de absorbância de todas as amostras obtidas em espectrofotômetro de feixe duplo, modelo CGB Cintra 20, operando com $10 \mathrm{~mm}$ de caminho ótico no comprimento de onda de $630 \mathrm{~nm}$ para o corante Azul Brilhante (FD\&C-1), seguindo a metodologia de Palladini (2000).

O experimento foi conduzido em delineamento de blocos ao acaso, com quatro repetições; cada parcela foi constituída de cinco linhas com amendoim, de $6 \mathrm{~m}$ de comprimento.

Os resultados das análises foram expressos em $\mu \mathrm{L} \mathrm{g}^{-1}$ de massa seca, pelo fato de a lavagem das amostras terem sido as plantas inteiras (folhas + caule), de acordo com proposta de Tomazela (2006). As análises estatísticas dos depósitos nas plantas de amendoim e da planta daninha foram realizadas separadamente por espécie, para evitar a interferência dos diferentes estádios de desenvolvimento, na comparação do desempenho das pontas avaliadas conforme metodologia descrita por Souza et al. (2007). Quanto à avaliação quantitativa dos depósitos, foram determinados os seguintes esquemas fatoriais: depósitos da pulverização em plantas de amendoim: fatorial duplo $8 \times 2$ (8 situações de pulverização x 2 estádios de desenvolvimento das plantas); depósitos da pulverização em plantas de Brachiaria plantaginea em ambos os estádios de desenvolvimento: fatorial duplo $8 \times 2$ (8 situações de pulverização x 2 posições - plantas presentes na linha e entrelinha da cultura do amendoim); e depósitos de calda de pulverização no solo (caixa gerbox) em ambos os estádios de desenvolvimento da cultura do amendoim: fatorial duplo 8 × 2 (8 situações de pulverização x 2 posições - coletores posicionados na linha e entrelinha da cultura do amendoim).

De acordo com os esquemas fatoriais estipulados, os resultados obtidos dos depósitos foram submetidos à análise de variância pelo teste F, e as médias, comparadas pelo teste LSD em nivel de $5 \%$ de probabilidade.

\section{RESULTADOS E DISCUSSÃO}

Os volumes médios de calda depositada no solo (caixa gerbox) durante a aplicação nas plantas de amendoim IAC Tatu-ST no estádio de desenvolvimento vegetativo (V1) estão apresentados na Tabela 2. Pode-se constatar que, apesar de as pontas de pulverização apresentarem tamanhos de gotas e volumes de aplicação diferentes, não houve efeito na deposição média do traçador em relação à posição dos coletores (caixa gerbox) posicionados no solo entre as linhas e entrelinhas da cultura durante a aplicação dos tratamentos nas plantas. Esse fato pode ter ocorrido provavelmente em razão de a variedade IAC Tatu ST ser de porte ereto, o que pode promover menor cobertura do solo pelas folhas, facilitando a chegada da gota ao solo. Além do hábito de crescimento, deve-se levar em consideração o estádio fenológico inicial da cultura; no estádio vegetativo (V1) a planta apresenta apenas a primeira folha composta na haste principal, com os folíolos abertos na horizontal. 
Berni et al. (1999), trabalhando com pontas do tipo jato plano e jato cônico, para avaliação da cobertura de pulverização nas culturas de feijão e milho, verificaram que na cultura do feijoeiro não houve diferença significativa da cobertura quando os coletores se encontravam na linha ou na entrelinha da cultura, quando aplicado aos 30 dias após o plantio, com volume de $200 \mathrm{~L} \mathrm{ha}^{-1}$, corroborando os resultados ora encontrados. Contudo, dados médios indicaram maior deposição na entrelinha. Os resultados encontrados para a cultura do milho aos 38 dias após o plantio foram significativos, havendo maior cobertura da pulverização quando os coletores estavam situados nas entrelinhas da cultura.

Observa-se que, mesmo não havendo diferenças estatísticas entre os depósitos, o posicionamento dos coletores (caixa gerbox) nas entrelinhas de semeadura da cultura do amendoim apresentou maior depósito médio, sendo superiores $8,2 \%$ em relação aos depósitos observados nos coletores posicionados na linha de semeadura da cultura. Ressalta-se que não

Tabela 2 - Volume médio de calda de pulverização depositada no solo (caixa gerbox) durante a aplicação em estádio vegetativo (V1) de desenvolvimento de plantas de amendoim, cultivar IAC Tatu ST, na linha e entrelinha da cultura. Botucatu-SP, 2006

\begin{tabular}{|c|c|c|c|c|}
\hline \multirow[t]{2}{*}{ Ponta } & $\begin{array}{c}\text { Volume de } \\
\text { pulverização }\end{array}$ & Linha & Entrelinha & \multirow[t]{2}{*}{ Média } \\
\hline & \multicolumn{3}{|c|}{$\left(\mathrm{L} \mathrm{ha}^{-1}\right)$} & \\
\hline XR 110015 VS & 150 & 73,38 & 94,53 & $83,95 \mathrm{de}$ \\
\hline XR 11002 VS & 200 & 111,18 & 111,48 & $111,33 \mathrm{bc}$ \\
\hline TX VK 6 & 150 & 61,50 & 94,63 & $78,06 \mathrm{e}$ \\
\hline TX VK 8 & 200 & 96,58 & 113,53 & $105,05 \mathrm{~cd}$ \\
\hline AI $110015 \mathrm{VS}$ & 150 & 122,70 & 133,75 & $128,23 \mathrm{ab}$ \\
\hline AI 11002 VS & 200 & 167,60 & 130,05 & $148,83 \mathrm{a}$ \\
\hline TJ60 11002 VS & 150 & 75,48 & 76,13 & $75,80 \mathrm{e}$ \\
\hline TJ60 $11002 \mathrm{VS}$ & 200 & 100,78 & 121,58 & $111,18 \mathrm{bc}$ \\
\hline Média & & 101,15 & 109,46 & \\
\hline $\mathrm{F}_{\text {Ponta }}(\mathrm{P})$ & $9,869^{* *}$ & & & \\
\hline $\mathrm{F}_{\text {Posição }}(\mathrm{Po})$ & $2,093^{\text {ns }}$ & & & \\
\hline $\mathrm{F}_{(\mathrm{P}) \times(\mathrm{Po})}$ & $1,756^{\mathrm{ns}}$ & & & \\
\hline $\mathrm{F}_{\text {Bloco }}$ & $1,087^{\mathrm{ns}}$ & & & \\
\hline DMS (P) & 23,140 & & & \\
\hline $\mathrm{CV}(\%)$ & 21,82 & & & \\
\hline
\end{tabular}

Médias seguidas de mesma letra na coluna não diferem estatisticamente entre si pelo teste LSD $(p \leq 0,05)$. ** valor significativo pelo teste $\mathrm{F}(\mathrm{p} \leq 0,01)$. ${ }^{\text {ns }}$ não significativo. houve interação significativa entre as pontas de pulverização e a posição em que se encontravam os coletores. Já para os valores médios dos depósitos em relação às pontas de pulverização, nota-se que as pontas AI 110015 VS e AI 11002 VS foram as que proporcionaram os maiores depósitos médios encontrados no solo, com valores de 128,23 e 148,83 $\mathrm{L} \mathrm{ha}^{-1}$, respectivamente. Isso pode ter ocorrido pelo fato de uma ponta de pulverização com indução de ar produzir gotas maiores com menor risco de deriva, proporcionando assim maior depósito médio. Esse fato também foi observado por Costa et al. (2008) em um estudo de dessecação de $B$. brizantha, em que os pesquisadores observaram maior deposição no solo proporcionada pela ponta AI 11002 VS, independentemente de ser estatisticamente semelhante aos demais tratamentos, proporcionando depósitos superiores de até $28,6 \%$, dependendo da ponta comparada. Os pesquisadores ressaltam ainda a importância de novos estudos com pontas de indução de ar para consolidação ou não desses maiores depósitos observados no solo.

Um aspecto importante desses resultados refere-se a uma possivel aplicação de herbicidas para controle de plantas daninhas na cultura do amendoim em pós-emergência, ou que possua efeito residual quando aplicado em pré-emergência, pois poderão promover também o controle do banco de semente; dessa forma, não seriam considerados perda os depósitos que alcançaram o solo. No entanto, essas aplicações podem apresentar maior risco de contaminação do solo, já que o alvo da pulverização seria a planta de amendoim. Esses resultados também podem ser extrapolados para aplicações de fungicidas e inseticidas no controle de doenças e pragas da cultura do amendoim.

Ressalta-se que, ao comparar o total aplicado e o total depositado no solo, para as plantas de amendoim, independentemente do volume de calda, os depósitos que alcançaram o solo no estádio vegetativo V1 foram entre 50,5 e 74,4\%. Chaim et al. (1999), em estudo que avaliou as perdas de pulverização nas culturas de feijão e tomate, verificaram que, dependendo do porte das plantas, a deposição variou entre 12 e $51 \%$, com perdas para o solo entre 30 e $74 \%$. 
Raetano \& Bauer (2004), trabalhando com deposição e perdas de calda de pulverização em feijoeiro, utilizando assistência de ar na barra pulverizadora com pontas do tipo jato plano e jato cônico vazio, verificaram que aos 26 DAE (dias após a emergência) das plantas as perdas para o solo foram elevadas, acima de $60 \%$ do volume aplicado, o que é comum em pulverizações nessa fase de desenvolvimento da planta.

Os valores médios da pulverização depositada no solo (caixa gerbox) - durante a aplicação em estádio reprodutivo (R2) de desenvolvimento de plantas de amendoim cultivar IAC Tatu ST na entrelinha da cultura - foram superiores aos encontrados na linha, independentemente da ponta e do volume aplicado (Tabela 3). Os depósitos obtidos na linha da cultura foram $26,2 \%$ menores em relação à quantidade verificada nos coletores que se encontravam na entrelinha da cultura. Esses resultados podem indicar que, quanto mais próximas das plantas de amendoim estiverem

Tabela 3 - Volume médio de calda de pulverização depositada no solo (caixa gerbox) durante a aplicação em estádio reprodutivo (R2) de desenvolvimento de plantas de amendoim, cultivar IACTatu ST, na linha e entrelinha da cultura. Botucatu-SP, 2006

\begin{tabular}{|c|c|c|c|c|}
\hline \multirow[t]{2}{*}{ Ponta } & $\begin{array}{l}\text { Volume de } \\
\text { pulverização }\end{array}$ & Linha & Entrelinha & \multirow[t]{2}{*}{ Média } \\
\hline & \multicolumn{3}{|c|}{$\left(\mathrm{L} \mathrm{ha}^{-1}\right)$} & \\
\hline XR 110015 VS & 150 & 28,88 & 40,78 & $34,83 \mathrm{bc}$ \\
\hline XR 11002 VS & 200 & 51,18 & 72,28 & $61,73 \mathrm{a}$ \\
\hline TX VK 6 & 150 & 14,83 & 25,35 & $20,09 \mathrm{~d}$ \\
\hline TX VK 8 & 200 & 32,80 & 29,58 & $31,19 \mathrm{c}$ \\
\hline AI 110015 VS & 150 & 30,15 & 31,15 & $30,65 \mathrm{~cd}$ \\
\hline AI 11002 VS & 200 & 24,38 & 39,48 & $31,93 \mathrm{c}$ \\
\hline TJ60 11002 VS & 150 & 24,05 & 29,75 & $26,90 \mathrm{~cd}$ \\
\hline TJ60 11002 VS & 200 & 32,90 & 55,78 & $44,34 \mathrm{~b}$ \\
\hline Média & & $29,89 \mathrm{~B}$ & $40,52 \mathrm{~A}$ & \\
\hline $\mathrm{F}_{\text {Ponta }}(\mathrm{P})$ & $11,205^{* *}$ & & & \\
\hline $\mathrm{F}_{\text {Posição }}(\mathrm{Po})$ & $15,635^{* *}$ & & & \\
\hline $\mathrm{F}_{(\mathrm{P}) \times(\mathrm{Po})}$ & $1,460^{\mathrm{ns}}$ & & & \\
\hline $\mathrm{F}_{\text {Bloco }}$ & $2,310^{\text {ns }}$ & & & \\
\hline DMS $(\mathrm{P})$ & 10,821 & & & \\
\hline DMS (Po) & 5,410 & & & \\
\hline $\mathrm{CV}(\%)$ & 30,52 & & & \\
\hline
\end{tabular}

Médias seguidas de mesma letra, maiúscula na linha e minúscula na coluna, não diferem estatisticamente entre si pelo teste LSD $(\mathrm{p} \leq 0,05) .{ }^{* *}$ valor significativo pelo teste $\mathrm{F}(\mathrm{p} \leq 0,01)$. ${ }^{\text {ns }}$ não significativo. as plantas daninhas, maior será a dificuldade de se atingir o alvo.

Os baixos valores dos depósitos de pulverização nos coletores posicionados na linha da cultura podem ter sido influenciados pelo efeito guarda-chuva das plantas de amendoim que se encontravam no estádio reprodutivo R2, apresentando folhas com todos os folíolos abertos, ou seja, o estádio reprodutivo R2 possui maior área foliar, o que cobriria a maior parte da superficie do solo, retendo assim os depósitos em suas folhas e agindo como uma barreira para as gotas.

Entre as pontas que proporcionaram os melhores depósitos médios da calda de pulverização sobre o solo, destaca-se a XR 11002 VS, seguida pela ponta TJ60 11002 VS, com depósitos médios de 61,73 e 44,34 $\mathrm{L} \mathrm{ha}^{-1}$, respectivamente, ambas com volume de aplicação de $200 \mathrm{~L} \mathrm{ha}^{-1}$.

Nota-se que o maior depósito médio encontrado no solo no estádio R2 das plantas de amendoim foi menos que metade da quantidade depositada no estádio V1 (61,73 vs. $\left.148,83 \mathrm{~L} \mathrm{ha}^{-1}\right)$. Esse fato deve-se ao maior dossel da cultura nesse estádio de desenvolvimento, o que determinou a interceptação de parte das gotas pulverizadas.

Ao comparar o total aplicado e o total depositado no solo, para as plantas de amendoim, independentemente do volume de calda, os depósitos que alcançaram o solo no estádio reprodutivo R2 ficaram entre 22,2 e 30,9\%.

$\mathrm{Na}$ Tabela 4, observa-se que, de forma geral, os volumes médios de calda depositada em plantas de amendoim IAC Tatu ST no estádio vegetativo V1 foram superiores aos depósitos encontrados no estádio reprodutivo R2, mesmo não havendo diferença estatística em algumas pontas testadas. Esse fato pode ter ocorrido em razão de as plantas de amendoim no estádio reprodutivo R2 e as plantas de $B$. plantaginea com 3-5 perfilhos proporcionarem acúmulo de folhas, com sobreposição destas, reduzindo assim o depósito por unidade de área foliar.

O maior valor médio do depósito da calda de pulverização alcançado as plantas de amendoim no estádio vegetativo V1 foi proporcionado pela ponta TX-VK 8 com volume de 
aplicação de $200 \mathrm{~L} \mathrm{ha}^{-1}$, sendo $161,2 \%$ superior ao menor depósito encontrado, que foi registrado com ponta TX-VK 6 em volume de aplicação de $150 \mathrm{~L} \mathrm{ha}^{-1}$. Já para as pulverizações no estádio reprodutivo $\mathrm{R} 2$, apesar de as pontas formarem gotas de tamanho diferentes e volumes de pulverização, não houve diferença na deposição média do marcador. Contudo, mesmo não havendo diferenças estatísticas, a ponta XR 11002 VS no volume de pulverização de $200 \mathrm{~L} \mathrm{ha}^{-1}$ proporcionou os maiores depósitos médios, sendo superior em $121 \%$ em relação à ponta AI 11002 VS no volume de aplicação de $200 \mathrm{~L} \mathrm{ha}^{-1}$, que proporcionou o menor depósito médio obtido.

Um fato interessante observado nos resultados obtidos refere-se ao comportamento do modelo de ponta com indução de ar AI. Mesmo não havendo diferenças significativas, registra-se que os depósitos proporcionados com volume de aplicação de $150 \mathrm{~L} \mathrm{ha}^{-1}$ foram superiores em $63,6 \%$ em relação aos obtidos pelo mesmo modelo de ponta quando utilizado volume de aplicação de $200 \mathrm{~L} \mathrm{ha}^{-1}$, indicando que nem sempre os maiores volumes proporcionam os maiores depósitos médios.

Tabela 4 - Volume médio de calda de pulverização depositada em plantas de amendoim, em dois estádios de desenvolvimento do cultivar IAC Tatu ST. Botucatu-SP, 2006

\begin{tabular}{|c|c|c|c|}
\hline \multirow{3}{*}{ Ponta } & \multirow{2}{*}{$\begin{array}{l}\text { Volume de } \\
\text { pulverização }\end{array}$} & \multicolumn{2}{|c|}{ Estádio } \\
\hline & & $\begin{array}{l}\text { Vegetativo } \\
\text { (V1) }\end{array}$ & $\begin{array}{l}\text { Reprodutivo } \\
\text { (R2) }\end{array}$ \\
\hline & $\left(\mathrm{L} \mathrm{ha}^{-1}\right)$ & \multicolumn{2}{|c|}{$\left(\mu \mathrm{Lg}^{-1}\right.$ de massa seca $)$} \\
\hline XR 110015 VS & 150 & $149,43 \mathrm{bcA}$ & $101,43 \mathrm{aA}$ \\
\hline XR 11002 VS & 200 & $110,49 \mathrm{bcA}$ & $114,80 \mathrm{aA}$ \\
\hline TX VK 6 & 150 & $96,44 \mathrm{cA}$ & $63,11 \mathrm{aA}$ \\
\hline TX VK 8 & 200 & $251,91 \mathrm{aA}$ & $70,44 \mathrm{aB}$ \\
\hline AI 110015 VS & 150 & $142,35 \mathrm{bcA}$ & $85,02 \mathrm{aA}$ \\
\hline AI 11002 VS & 200 & $171,20 \mathrm{bA}$ & $51,95 \mathrm{aB}$ \\
\hline TJ60 11002 VS & 150 & $147,27 \mathrm{bcA}$ & $69,67 \mathrm{aB}$ \\
\hline TJ60 11002 VS & 200 & $152,71 \mathrm{bcA}$ & $72,88 \mathrm{aB}$ \\
\hline $\mathrm{F}_{\text {Ponta }}(\mathrm{P})$ & $2,000^{\mathrm{ns}}$ & & \\
\hline $\mathrm{F}_{\text {Estádio }}(\mathrm{E})$ & $43,339^{* *}$ & & \\
\hline $\mathrm{F}_{(\mathrm{P}) \mathrm{x}}(\mathrm{E})$ & $3,158^{* *}$ & & \\
\hline $\mathrm{F}_{\text {Bloco }}$ & $0,414^{\text {ns }}$ & & \\
\hline $\mathrm{DMS}(\mathrm{P} \times \mathrm{E})$ & 64,091 & & \\
\hline CV $(\%)$ & 38,90 & & \\
\hline
\end{tabular}

Médias seguidas de mesma letra, maiúscula na linha e minúscula na coluna, não diferem estatisticamente entre si pelo teste LSD $(\mathrm{p} \leq 0,05)$. ** valor significativo pelo teste $\mathrm{F}(\mathrm{p} \leq 0,01)$. ${ }^{\text {ns }}$ não significativo.
Na Tabela 5 encontram-se os resultados do volume médio de calda depositada em plantas de Brachiaria plantaginea no estádio de 1-2 perfilhos, presentes na linha de plantio da cultura de amendoim, do cultivar IAC Tatu ST.

No geral, observa-se que os depósitos médios nas plantas de capim-marmelada que se encontravam na linha de semeadura da cultura de amendoim foram superiores ou não diferiram estatisticamente daqueles obtidos em plantas que se situavam na entrelinha da cultura, independentemente da ponta em teste. Resultado semelhante foi encontrado por Souza et al. (2007), em que aproximadamente $80 \%$ da população total de plantas de $B$. plantaginea apresentou maior quantidade de depósito na linha - resultado inverso ao esperado; no entanto, quando os pesquisadores padronizaram as plantas daninhas nas diferentes posições em que se encontram dentro de um mesmo intervalo de área foliar, observaram-se depósitos maiores naquelas situadas na entrelinha, e as diferenças tornaram-se mais evidentes, revelando também a interferência do estádio de desenvolvimento sobre os depósitos.

Tabela 5 - Volume médio de calda depositada no estádio de desenvolvimento de 1-2 perfilhos de plantas de Brachiaria plantaginea. Botucatu-SP, 2006

\begin{tabular}{|c|c|c|c|}
\hline Ponta & $\begin{array}{l}\text { Volume de } \\
\text { pulverização }\end{array}$ & Linha & Entrelinha \\
\hline & $\left(\mathrm{L} \mathrm{ha}^{-1}\right)$ & \multicolumn{2}{|c|}{$\left(\mu \mathrm{L} \mathrm{g}^{-1}\right.$ de massa seca) } \\
\hline XR 110015 VS & 150 & $273,55 \mathrm{cdA}$ & $105,23 \mathrm{aA}$ \\
\hline XR 11002 VS & 200 & $937,47 \mathrm{aA}$ & $219,83 \mathrm{aB}$ \\
\hline TX VK 6 & 150 & $115,43 \mathrm{dA}$ & $160,97 \mathrm{aA}$ \\
\hline TX VK 8 & 200 & $192,31 \mathrm{cdA}$ & $98,13 \mathrm{aA}$ \\
\hline AI $110015 \mathrm{VS}$ & 150 & $340,15 \mathrm{cA}$ & $77,35 \mathrm{aB}$ \\
\hline AI 11002 VS & 200 & $207,11 \mathrm{cdA}$ & $73,15 \mathrm{aA}$ \\
\hline TJ60 11002 VS & 150 & $648,63 \mathrm{bA}$ & $220,89 \mathrm{aB}$ \\
\hline TJ60 $11002 \mathrm{VS}$ & 200 & $119,76 \mathrm{dA}$ & $140,24 \mathrm{aA}$ \\
\hline $\mathrm{F}_{\text {Ponta }}(\mathrm{P})$ & $12,684 * *$ & & \\
\hline $\mathrm{F}_{\text {Posição }}(\mathrm{Po})$ & $42,506^{* *}$ & & \\
\hline$F_{(P) \times(P o)}$ & $7,181 * *$ & & \\
\hline$F_{\text {Bloco }}$ & $0,269^{\text {ns }}$ & & \\
\hline $\mathrm{DMS}(\mathrm{PxPo})$ & 189,896 & & \\
\hline $\mathrm{CV}(\%)$ & 54,28 & & \\
\hline
\end{tabular}

Médias seguidas de mesma letra, maiúscula na linha e minúscula na coluna, não diferem estatisticamente entre si pelo teste LSD $(\mathrm{p} \leq 0,05) .{ }^{* *}$ valor significativo pelo teste $\mathrm{F}(\mathrm{p} \leq 0,01)$. ${ }^{\mathrm{ns}}$ não significativo.

Planta Daninha, Viçosa-MG, v. 30, n. 1, p. 201-209, 2012 
Nota-se que o maior depósito médio encontrado em plantas de $B$. plantaginea no estádio vegetativo de 1-2 perfilhos situadas na linha da cultura do amendoim foi proporcionado pela ponta XR $11002 \mathrm{VS}\left(937,47 \mu \mathrm{L} \mathrm{g}^{-1}\right.$ de massa seca) no volume de aplicação de $200 \mathrm{~L} \mathrm{ha}^{-1}$; já as plantas situadas na entrelinha da cultura proporcionaram depósitos semelhantes, não havendo diferenças estatísticas em relação ao tipo de ponta e volume de aplicação. O menor depósito médio encontrado nas plantas de capim-marmelada foi proporcionado pela ponta TX VK $6\left(115,43 \mu \mathrm{L} \mathrm{g}^{-1}\right.$ de massa seca) com volume de pulverização de $150 \mathrm{~L}$ ha ${ }^{1}$, sendo $87,7 \%$ inferior ao maior depósito encontrado. Não foram observadas diferenças significativas nos depósitos encontrados nas plantas situadas nas entrelinhas da cultura - resultado semelhante ao observado nas plantas com estádio de desenvolvimento de 1-2 perfilhos. Uma das possiveis razões de não haver diferença estatística nas plantas situadas na entrelinha da cultura pode ser o fato de as plantas não sofrerem o efeito guarda-chuva, o qual as plantas situadas na linha da cultura sofrem com as plantas de amendoim; isso ressalta a importância de se conhecer a melhor ponta que proporcione a chegada eficiente das gotas nessas plantas.

Esses resultados corroboram os obtidos por Maciel et al. (2001), que constataram maiores depósitos em plantas de feijão proporcionados pela ponta XR 11002 VS, em relação à ponta TX-4 VS, no volume de aplicação de $100 \mathrm{~L} \mathrm{ha}^{-1}$.

$\mathrm{Na}$ Tabela 6 são apresentados os resultados médios do volume de calda depositada no estádio de desenvolvimento de 3-5 perfilhos de plantas de $B$. plantaginea. Não foi observada diferença significativa nos depósitos encontrados nas plantas que estavam situadas nas linhas e entrelinhas da cultura.

Observa-se que, de modo geral, os depósitos médios encontrados na entrelinha da cultura foram mais uniformes e maiores que os encontrados na linha da cultura, com exceção dos modelos de ponta XR e AI 110015 VS a $150 \mathrm{~L} \mathrm{ha}^{-1}$, que proporcionaram depósitos superiores na linha da cultura.

Nas condições em que o presente trabalho foi desenvolvido, pode-se concluir que houve incrementos nos depósitos de gotas nas plantas
Tabela 6 - Volume médio de calda depositada no estádio de desenvolvimento de 3-5 perfilhos de plantas de Brachiaria plantaginea. Botucatu-SP, 2006

\begin{tabular}{|c|c|c|c|}
\hline Ponta & $\begin{array}{l}\text { Volume de } \\
\text { pulverização }\end{array}$ & Linha & Entrelinha \\
\hline & $\left(\mathrm{L} \mathrm{ha}^{-1}\right)$ & \multicolumn{2}{|c|}{$\left(\mu \mathrm{L} \mathrm{g}^{-1}\right.$ de massa seca) } \\
\hline XR 110015 VS & 150 & 477,24 & 135,96 \\
\hline XR 11002 VS & 200 & 154,87 & 130,93 \\
\hline TX VK 6 & 150 & 71,67 & 178,48 \\
\hline TX VK 8 & 200 & 117,13 & 320,03 \\
\hline AI 110015 VS & 150 & 136,64 & 123,57 \\
\hline AI $11002 \mathrm{VS}$ & 200 & 82,69 & 123,69 \\
\hline TJ60 $11002 \mathrm{VS}$ & 150 & 73,90 & 129,82 \\
\hline TJ60 $11002 \mathrm{VS}$ & 200 & 149,35 & 223,39 \\
\hline $\mathrm{F}_{\text {Ponta }}(\mathrm{P})$ & $1,200^{\mathrm{ns}}$ & & \\
\hline $\mathrm{F}_{\text {Posição }}(\mathrm{Po})$ & $0,080^{\text {ns }}$ & & \\
\hline $\mathrm{F}_{(\mathrm{P}) \times(\mathrm{Po})}$ & $1,556^{\mathrm{ns}}$ & & \\
\hline $\mathrm{F}_{\text {Bloco }}$ & $0,925^{\mathrm{ns}}$ & & \\
\hline CV $(\%)$ & 110,27 & & \\
\hline
\end{tabular}

Médias seguidas de mesma letra, maiúscula na linha e minúscula na coluna, não diferem estatisticamente entre si pelo teste LSD $(\mathrm{p} \leq 0,05) .{ }^{* *}$ valor significativo pelo teste $\mathrm{F}(\mathrm{p} \leq 0,01)$. ${ }^{\text {ns }}$ não significativo.

de amendoim IAC Tatu ST em ambos os estádios de desenvolvimento da cultura, com a utilização dos maiores volumes de calda de pulverização, com exceção das pontas XR 110015 VS e AI1 1002 VS nos estádios vegetativo $\mathrm{V} 1$ e reprodutivo $\mathrm{R} 2$ da cultura, respectivamente. As maiores perdas de gotas para o solo nas pulverizações no estádio vegetativo V1 foram proporcionadas pelas pontas AI 110015 VS e AI 11002 VS; no estádio reprodutivo R2, a maior perda foi promovida pela ponta XR 11002 VS. Quanto à deposição de gotas nas plantas de B. plantaginea, as pontas XR $11002 \mathrm{VS}$, AI 110015 VS e TJ60 11002 VS (150 L ha-1) proporcionaram os maiores depósitos nas plantas presentes na linha, em relação às da entrelinha da cultura, nas aplicações no estádio vegetativo V1; contudo, no estádio reprodutivo R2, as pontas mostraram comportamento semelhante na deposição de gotas em $B$. plantaginea, independentemente da sua posição em relação à cultura do amendoim.

\section{LITERATURA CITADA}

AGOSTINHO, F. H. et al. The effect of cultivar on critical periods of weed control in peanuts. Peanut Sci., v. 33, n. 1, p. 29-35, 2006. 
BERNI, R. F. et al. Avaliação da cobertura de gotas provocada por diferentes bicos de pulverização na cultura do milho e do feijão. Pesq. Agropec. Trop., v. 29, n. 1, p. 49-52, 1999.

BOOTE, K. J. Growth stages of peanut (Arachis hypogaea L.). Peanut Sci., v .9, n. 1, p. 35-39, 1982.

CHAIM, A. et al. Avaliação de perdas de pulverização em culturas de feijão e tomate. Jaguariúna: Embrapa-CNPMA, 1999. 29 p. (Boletim de Pesquisa, 2).

CHAIM, A.; VALARINI, P. J.; PIO, L. C. Avaliação de perdas na pulverização de agrotóxicos na cultura do feijão. Pesticidas: R. Ecotoxicol. Meio Amb., v. 10, n. 1, p. 65-74, 2000.

COSTA, N. V. et al. C. Efeito de pontas de pulverização na deposição e na dessecação em plantas de Brachiaria brizantha. Planta Daninha, v. 26, n. 4, p. 923-933, 2008.

DIAS, T. C. S. et al. Efeito do espaçamento entre fileiras de amendoim rasteiro na interferência de plantas daninhas na cultura. Planta Daninha, v. 27, n. 2, p. 221-228, 2009.

\section{EMPRESA BRASILEIRA DE PESQUISA}

AGROPECUÁRIA - EMBRAPA. Centro nacional de pesquisa de solos. Sistema brasileiro de classificação de solos. Brasília: Embrapa Produção de Informação; Rio de Janeiro: Embrapa Solos, 1999. 412 p.

\section{FUNDAÇÃO INSTITUTO BRASILEIRO DE} GEOGRAFIA E ESTATÍSTICA - IBGE. Levantamento sistemático da produção agrícola: pesquisa mensal de previsão e acompanhamento das safras agrícolas no ano civil. julho, 2010. $122 \mathrm{p}$.

FARINHA, J. V. et al. Deposição da calda de pulverização em cultivares de soja no estádio R1. Ci. Rural, v. 39, n. 6, p. 1738-1744, 2009.

HOLLOWAY, P. J. Surface factors affecting the wetting of leaves. Pestic. Sci., v. 1, n. 1, p. 56-63, 1970.

KASAI, F. S. et al. Efeitos dos períodos de competição do mato na cultura do amendoim: I safra da seca de 1988. Bragantia, v. 56, n. 2, p. 323-331, 1997.
MACIEL, C. D. G. et al. Avaliação do depósito e distribuição da calda de pulverização em plantas de feijoeiro e Brachiaria decumbens. Planta Daninha, v. 19, n. 1, p. 103-110, 2001.

PALLADINI, L. A. Metodologia para avaliação da deposição em pulverizações. Botucatu, SP, 2000. 111 f. Tese (Doutorado em Agronomia/Proteção Vegetal) Faculdade de Ciências Agronômicas, Universidade Estadual Paulista, Botucatu, 2000.

PERGHER, G.; GUBIANI, R. The effect of spray application rate on foliar deposition in a hedgerow vineyard. J. Agric. Eng.Res., v. 61, n. 3, p. 205-216, 1995.

PERGHER, G.; GUBIANI, R.; TONETTO, G. Foliar deposition and pesticide losses from three air-assisted sprayers in a hedgerow vineyard. Crop Protec., v. 16, n. 1, p. 25-33, 1997.

RAETANO, C. G.; BAUER, F. Deposição e perdas da calda em feijoeiro em aplicação com assistência de ar na barra pulverizadora. Bragantia, v. 63, n. 2, p. 309-315, 2004.

RODRIGUES, A. C. P. et al. Variáveis qualitativas da pulverização em feijão, Bidens pilosa e Brachiaria plantaginea. Ci. Agrotec., v. 34, n. 3, p. 698-707, 2010.

SOUZA, R. T.; VELINI, E. D.; PALLADINI, L. A. Aspectos metodológicos para análise de depósitos de pulverizações pela determinação dos depósitos pontuais. Planta Daninha, v. 25, n. 1, p. 195-202, 2007.

SPRAYING SYSTEMS. Teejet spray products: guia do comprador 202-BR/P. Wheaton: Spraying Systems, 2003. 37 p.

TAYLOR, W. A.; SHAW, G. B. The effect of drop speed, size and surfactant on the deposition of spray on barley and radish or mustard. Pestic. Sci., v. 14, n. 6, p. 659-65, 1993.

TOMAZELA, M.S. et al. Avaliação da deposição da calda de pulverização em função da densidade populacional de Brachiaria plantaginea, do volume e do ângulo de aplicação. Planta Daninha, v. 24, n. 1, p. 183-189, 2006.

VILLALBA, J. et al. Depósito del caldo de aspersión de distintos tipos de boquillas en dos cultivares de soya en el estadio V3. Agrociencia, v. 43, n. 5, p. 465-473, 2009. 